\title{
ANALISIS KETERKAITAN IMPLEMENTASI MLC 2006 DENGAN KESEJAHTERAAN PELAUT
}

\author{
Aries Allolayuk ${ }^{1)}$ Welem Ada ${ }^{2)}$ Masrupah ${ }^{3)}$ Endang ${ }^{4)}$ \\ Politeknik IImu Pelayaran Makassar \\ Jalan Tentara Pelajar No. 173 Makassar, Kode pos. 90172 \\ Telp. (0411) 3616975; Fax (0411) 3628732 \\ E-mail: pipmks@pipmakassar.com
}

\begin{abstract}
ABSTRAK
Sesuai dengan kebiasaan internasional, sebuah konvensi multilateral tidak dapat diberlakukan seketika, menunggu sampai sejumlah anggota meratifikasi konvensi tersebut. Sesuai dengan salah satu artikel pada MLC (maritime Labour Convention) 2006, konvensi ini baru bisa diberlakukan (come into force) satu tahun setelah 30 negara anggota atau sejumlah negara yang mewakili 33\% gross tonnage armada internasional telah meratifikasinya. Pada bulan agustus 2012 telah mencapai target yang telah meratifikasi konvensi ini maka secara aturan pada tanggal 20 agustus 2013 aturan ini telah harus diterapkan secara internasional. Penelitian ini di laksanakan Di MV. Aisling Milik PT. cabang Batam agent perusahaan Taiwan yang berkantor pusat Singapore bertujuan untuk fokus mengetahui dan memahami penerapan MLC sebagai konvensi hak asasi pelaut yang baru, yang harus di terapkan di kapal internasional maupun di kapal yang melayari perairan Indonesia (domestik). Dengan menggunakan Metode Analisis Deskriptif. Hasil yang didapatkan adalah bahwa tingkat kesejahteraan awak kapal yang bekerja di atas kapal MV. Aisling ,masih berada dalam kurang sejahtera untuk tingkat anak buah kapal, tetapi untuk tingkat perwira , mereka berada dalam sejahtera.. jika di presentasekan bahwa 40\% ,adalah anak buah kapal berada dalam kurang sejahtera, sedangkan sejahtera ada ada $30 \%$ ,sedangkan sangat sejahtera ada $20 \%$,dan cukup sejahtera ada $10 \%$, jadi jika di simpulkan yang terbanyak adalah $40 \%$ berada dalam kurang sejahtera.
\end{abstract}

Kata Kunci : Implementasi Mlc, Kesejahteraan, Pelaut 


\section{PENDAHULUAN}

Sesuai dengan kebiasaan internasional, sebuah konvensi multilateral tidak dapat diberlakukan seketika, menunggu sampai sejumlah anggota meratifikasi konvensi tersebut. Sesuai dengan salah satu artikel pada MLC 2006, konvensi ini baru bisa diberlakukan (come into force) satu tahun setelah 30 negara anggota atau sejumlah negara yang mewakili $33 \%$ gross tonnage armada internasional telah meratifikasinya. Pada bulan agustus 2012 telah mencapai target yang telah meratifikasi konvensi ini maka secara aturan pada tanggal 20 agustus 2013 aturan ini telah harus diterapkan secara internasional. Pada tanggal 6 Oktober 2016, Republik Indonesia selaku negara maritim telah mengesahkan aturan ini dan menjadikannya Undang Undang Negara Republik Indonesia Nomor 15 Tahun 2016. antara lain:

1. Mengenai Ketidak sesuaian Upah

Di dalam PKL tertera bahwa gaji terhitung dalam mata uang (US dollar) namun ternyata dalam pembayaranya dibayarkan dalam hitungan kurs indonesia yang mana ketika terjadi ketidak stabilan Dollar sebagai patokan mata uang dunia, pembayaran upah tetap yaitu jumlah dollar dikalikan jumlah kurs yang diberikan perusahaan dan transparansi mengenai kurs dollar terhadap rupiah pun tidak diberikan bahkan nota pembayaran gaji pun tidak ada.

2. Jam Kerja Yang Melewati Batas Yang Ditetapkan Oleh MLC 2006.

Sesuai dengan aturan MLC 2006, Batas maksimal jam kerja dalam sehari adalah 14 jam dalam periode 24 jam dan 72 jam pada periode tujuh hari. Batas minimum jam istirahat adalah tidak kurang dari 10 jam dalam satu hari dan 77 jam pada periode tujuh hari. Jam istirahat harus dibagi tidak lebih dari dua periode dan salah satunya harus istirahat enam jam. Interval dari jam istirahat yang satu dan yang lainnya tidak boleh melewati 14 jam. 
Pada contoh kasus di atas patutlah kita anggap bahwa pelaut belum mendapatkan perhatian lebih atas jenis pekerjaannya. Berdasarkan latar belakang dan fenomena diatas, maka penulis tertarik untuk mengangkat karya tulis ilmiah dengan judul "Analisis Keterkaitan Implementasi MLC 2006 dengan Kesejahteraan Pelaut ".

Berdasarkan latar belakang di atas, maka permasalahan yang dirumuskan pada penulisan ini adalah bagaimanakah Implementasi MLC sebagai konvensi dengan kesejahteraan pelaut?

Agar tidak terlalu kompleks dan pembahasan yang lebar berdasarkan latar belakang dan rumusan masalah diatas, maka penulis membatasi pada penerapan MLC 2006 dengan kesejahteraan pelaut yang belum sesuai dengan aturan tersebut.

Penulis bertujuan untuk fokus mengetahui dan memahami penerapan MLC sebagai konvensi hak asasi pelaut yang baru, yang harus di terapkan di kapal internasional maupun di kapal yang melayari perairan Indonesia (domestik).

Di dalam karya ilmiah terapan ini penulis sangat mengharapkan bahwa nantinya hasil dari tulisan ini dapat :

1. Memberikan tambahan ilmu bagi penulis, pelaut dan calon pelaut khususnya lingkup akademika Politeknik IImu Pelayaran Makassar, dan juga para pembaca pada umumnya. Agar memahami dan mengetahui tentang hak asasi sebagai seorang pelaut.

2. Sebagai bahan pandangan kepada Pemerintah indonesia, INSA (Indonesia Nasional Shipowner Association) dan juga crewing shipping agency tentang MLC agar dapat mendukung dan melancarkan proses penerapan konvensi hak asasi pelaut ini, khususnya sebagai perlindungan kepada pelaut nasional indonesia berdasarkan pengalaman yang penulis dapati di kapal internasional. 
Berdasarkan rumusan masalah di atas maka penulis merumuskan hipotesis yaitu, diduga aturan MLC 2006 di atas kapal belum dilaksanakan sebagaimana mestinya pada kapal-kapal.

\section{KAJIAN PUSTAKA}

\subsection{Definisi Dari MLC Konvensi}

Tanggal 20 Agustus 2012 persyaratan tersebut telah terpenuhi setelah Rusia dan Philippines meratifikasi konvensi tersebut sehingga MLC 2006 dapat diberlakukan mulai tanggal 20 Agustus 2013. Negara yang telah meratifikasi tersebut yaitu: Croatia, Bulgaria, Canada, Saint Vincent and the Grenadines, Switzerland, Benin, Singapore, Denmark, Antigua and Barbuda, Latvia, Luxembourg, Kiribati, Netherlands, Australia, St Kitts and Nevis, Tuvalu, Togo, Poland, Palau, Sweden, Cyprus, Russian Federation, Philippines. Menyusul kemudian Negara-negara Eropa lain yaitu, Finlandia Januari 2013, Malta Januari 2013, Yunani Februari 2013 dan Perancis Februari 2013.

Beberapa ketentuan MLC tercantum dalam regulasi nasional, antara lain dalam Kitab Undang-Undang Hukum Dagang (Buku II), UU 13/2003 (Ketenagakerjaan), UU 17/2008 (Pelayaran), Peraturan Pemerintah (PP) No.7/2000 tentang kepelautan, PP No20/2010 tentang angkutan di perairan dan PP No.51/2012 tentang peningkatan SDM Pelaut yang mensyaratkan kesejahteraan.

\section{2. Organisasi di atas kapal}

Khusus Indonesia jika menyingkapi dari MLC maka Indonesia segera meratifikasi pada tanggal 6 oktober 2016 , Sehingga MLC ini lambat di ratifikasi karena melihat kondisi perusahaan domestic masih belum memenuhi standard dari segala segi .nanti setelah pemerintahaan Presiden Indonesia Joko Widodo, MLC 2006 diratifikasi secara resmi oleh presiden Republik Indonesia pada tanggal 6 Oktober 2016 dan menjadikannya Undang - Undang No. 15 Tahun 2016. 
Kebijakan luar negeri jika dikaitkan dengan pengratifikasian Maritime Labour Convention MLC ini, maka suatu negara di hadapi pada dua pilihan. Pilihan tersebut adalah apakah negara itu meratifikasi atau tidak dan apakah keuntungan yang diperoleh negara itu jika meratifikasinya dan apa pula kerugian jika tidak meratifikasi.

Aturan DMLC setiap kapal yang beroperasi di perairan internasional antar pelabuhan di negara yang berbeda, harus memiliki sertifikat buruh maritim, kecuali dari aturan MLC sendiri yaitu:

a. Kapal yang berlayar secara eksklusif di perairan sungai dan danau, pelayaran-pelayaran pesisir dalam perairan teluk atau wilayah-wilayah dimana regulasi pelabuhan berlaku.

b. Kapal perikanan.

c. Kapal yang dibangun secara tradisional seperti sampan atau kapal layar tradisional.

d. Kapal perang, kapal negara dan kapal perawatan militer. Kapal yang berbobot 200GT, dan tidak berlayar secara internasional dapat dikecualikan oleh negara bendera dari beberapa kewajiban jika hak-hak pelautnya sudah dilindungi oleh undang-undang nasional. 
Gambar 2.1 Pemberlakuan Proses MLC

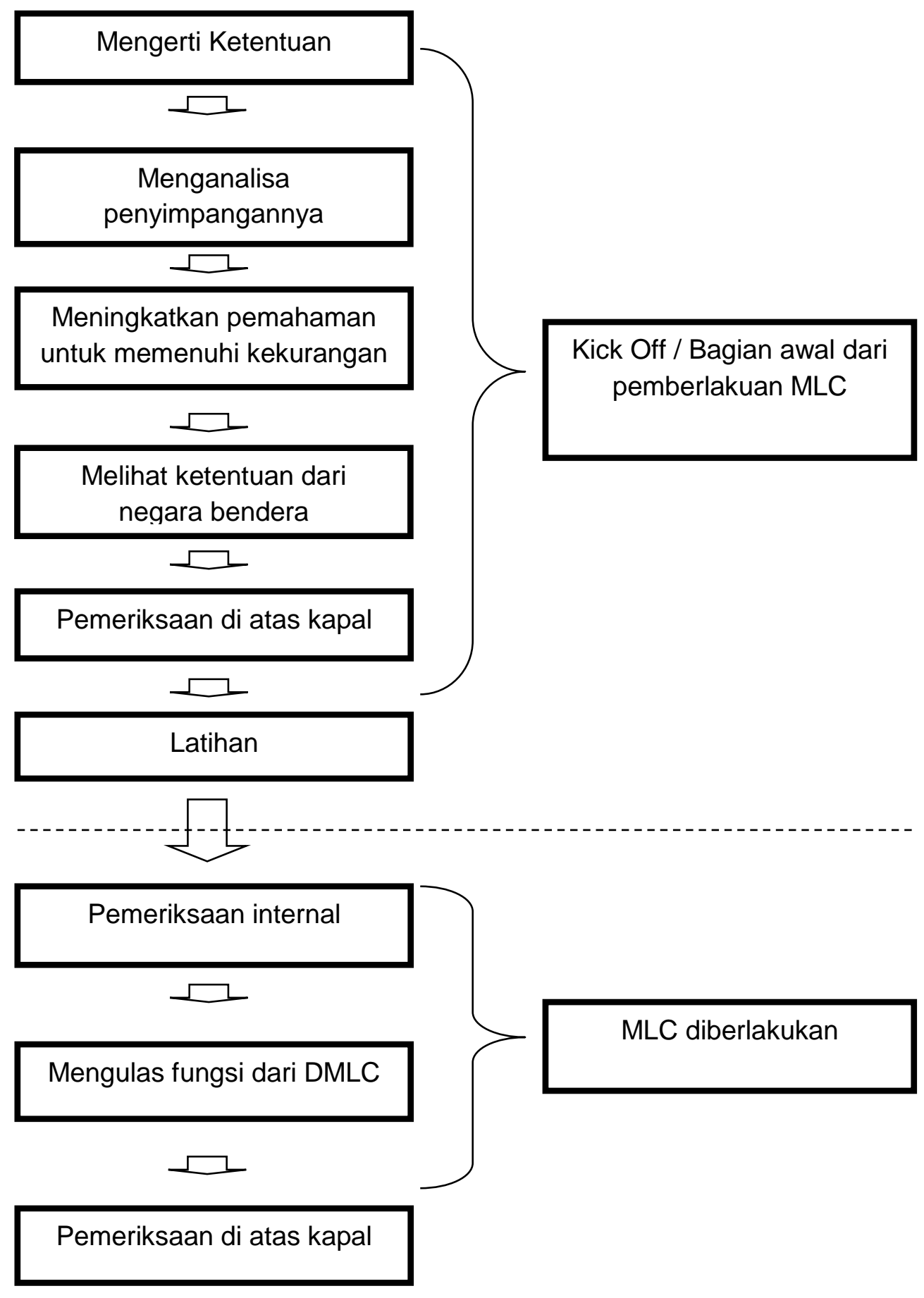

Sumber : Peningkatan Kompleksitas AS DNV.GL 2011 


\section{METODE PENELITIAN}

Penelitian ini di laksanakan Di MV. Aisling Milik Pt cabang Batam agent.perusahaan Taiwan yang berkantor pusat Singapore, Waktu penelitian di laksanakan 3 hari mulai dari tanggal 11/07/2018 s/d tanggal $13 / 07 / 2018$

Penulisan penelitian ini di butuhkan data pendukung sebagai bahan observasi untuk merumuskan masalah yang terjadi. Adapun metode yang penulis gunakan adalah :Metode Survey (Observasi ) dan Metode Interview

Data Kualitatif bersumber pada :

a. Observasi

b. Angket ( quuestionaire )

Metode angket adalah suatu daftar yang berisikan rangkaian pertanyaan sesuatu masalah atau bidang yang di teliti.

$$
P=\quad \mathrm{N} \times 100 \%
$$

$\mathrm{P}=$ Persentase.

$\mathrm{F}=$ Jumlah responden.

$\mathrm{N}=$ Jumlah responden seluruhnya.

Dari hasil jawaban responden seluruhnya sebelum dan setelah ini akan di kategorikan sebagai berikut :

$0 \%-25 \%=$ Tidak sejahtera.

$26 \%-42 \%=$ Kurang sejahtera.

$43 \%-65 \%=$ Cukup sejahtera.

$66 \%-80 \%=$ sejahtera

$81 \%-100 \%=$ Sangat sejahtera.

Dari rentang nilai di atas dapat memberikan penilaian mengenai tingkat anak buah kapal dalam memahami tentang analisis 
kesejahteraan dari tingkat pengahasilan dan tempat tinggal di kapal.,setelah hasil angket ini di olah menurut kategorisasi yang di kemukakan oleh Azwar ( 1999 ).

Populasi Yang berjumlah 18 orang. Anak buah kapal Aisling yang menjadi sumber penelitian. Sampel yang di ambil adalah 10 orang anak buah kapal yang menjadi responden.

Adapun langkah2 yang di lakukan antara lain : Mencatat jumlah awak kapal secara keseluruhaan, memilih sampel, memberikan kuesioner dengan beberapa criteria penilaian dari hasil

\section{HASIL PENELITIAN DAN PEMBAHASAN}

\subsection{Kurangnya Kesejahteraan Pelaut :}

\section{a. Gaji Awak kapal. MV Aisling :}

Standard gaji yang di berikan tidak sesuai dengan standard international ,hal ini di sebabkan perusahaan kapal ini yang tidak memenuhi standard gaji masih di bawah rata-ratagaji yang diterimanya.

Gaji yang diberikan dapat dilihat pada table di bawah ini :

Tabel 4.1 Standard gaji yang diberikan :

\begin{tabular}{|l|l|l|l|}
\hline No. & $\begin{array}{l}\text { Standard Internasional } \\
(\text { US })\end{array}$ & MV. Aisling (US) & Ket. \\
\hline 1. & $2500-3500$ & $2000-3000$ & Mualim II \\
\hline & $3500-4500$ & $3000-4000$ & Mualim I \\
\hline & $4500-7500$ & $4000-6000$ & Capten \\
\hline
\end{tabular}

Sumber : MV. Kapal Aisling

\section{b. Waktu Istirahat :}

Waktu istirahat awak kapal dalam MLC adalah Maksimal jam kerja adalah 14 jam dalam sehari atau 72 jam dalam seminggu atau jam istirahat minimal adalah 10 jam dalam sehari atau 77 jam dalam seminggu. Selanjutnya, waktu istirahat tidak boleh dibagi menjadi lebih dari 2 periode dimana setidaknya 6 jam waktu istirahat harus diberikan secara berurutan dalam satu dari dua, Pada kapal MV 
Aisling dalam keadaan Emergency waktu kerja sampai dengan 20 Jam sehari berarti dalam seminggu140 Jam. Pada keadaan biasa sama dengan ketentuan MLC.

\section{Akomodasi/Tempat tinggal di kapal.}

Jika mengamati secara langsung tempat tinggal di atas kapal Aisling sangat tidak memenuhi standard kelayakan di mana kamar- kamar Awak kapal tidak di lengkapi air pendingin hanya nakhoda saja dan mualim satu serta Kepala kamar mesin, sehingga akodomasi dari awak kapal di katakan tidak memenuhi persyaratan.
a. Permakanan:
b. Perlindungan dan Perawatan Kesehatan,
c. Perawatan Medis di kapal

Table 4.2 Tabulasi data Penelitian MV. Aisling Untuk Kesejahteraan.

\begin{tabular}{|l|c|c|c|c|c|c|c|c|c|c|c|}
\hline Subjek / item & \multicolumn{10}{|c|}{ Jumlah soal } \\
\cline { 2 - 12 } & 1 & 2 & 3 & 4 & 5 & 6 & 7 & 8 & 9 & 10 & \\
\hline Mualim I & 10 & 0 & 10 & 10 & 10 & 0 & 10 & 10 & 10 & 10 & 80 \\
\hline Mualim II & 10 & 10 & 10 & 10 & 0 & 0 & 0 & 10 & 10 & 10 & 70 \\
\hline Mualim III & 10 & 0 & 10 & 10 & 10 & 0 & 0 & 10 & 0 & 10 & 60 \\
\hline bosun & 10 & 0 & 10 & 10 & 10 & 10 & 0 & 0 & 0 & 10 & 50 \\
\hline koki & 10 & 10 & 0 & 10 & 10 & 0 & 0 & 0 & 10 & 0 & 50 \\
\hline K.K.M & 10 & 10 & 10 & 10 & 0 & 10 & 10 & 10 & 10 & 0 & 80 \\
\hline Masinis I & 10 & 0 & 10 & 10 & 10 & 10 & 10 & 0 & 10 & 0 & 70 \\
\hline Masinis II & 10 & 10 & 0 & 0 & 10 & 10 & 10 & 0 & 0 & 10 & 60 \\
\hline Electrisien & 10 & 0 & 10 & 0 & 10 & 0 & 10 & 0 & 10 & 0 & 40 \\
\hline Jurumudi & 10 & 0 & 10 & 0 & 10 & 0 & 10 & 0 & 0 & 0 & 40 \\
\hline
\end{tabular}

Sumber data hasil olah data MV, Aisling 2018 
Tabel 4.3 Presentase dan Kategorisasi hasil penelitian Mv. Aisling

\begin{tabular}{|l|l|c|c|c|l|}
\hline No. & responden & nilai & $\begin{array}{l}\text { Skor } \\
\text { total }\end{array}$ & $\begin{array}{c}\text { Presentase } \\
(\%)\end{array}$ & kategori \\
\hline 1 & Mualim I & 10 & 90 & 90 & Sangat sejahtera \\
\hline 2 & Mualim II & 7 & 70 & 70 & sejahtera \\
\hline 3 & Mualim III & 6 & 60 & 60 & Cukup sejahtera \\
\hline 4 & bosun & 5 & 50 & 50 & Kurang sejahtera \\
\hline 5 & koki & 5 & 50 & 50 & Kurang sejahtera \\
\hline 6 & K.K.M & 8 & 90 & 90 & Sangat sejahtera \\
\hline 7 & Masinis I & 7 & 70 & 70 & sejahtera \\
\hline 8 & Masinis II & 7 & 70 & 70 & sejahtera \\
\hline 9 & Electrisien & 4 & 40 & 40 & Kurang sejahtera \\
\hline 10 & Jurusan & 4 & 40 & 40 & Kurang sejahtera \\
\hline
\end{tabular}

Sumber data hasil olah data MV, Aisling 2018

Table 4.4 tingkat kesejahteraan awak kapal Aisling

\begin{tabular}{|l|l|c|c|}
\hline No & Kondisi awak kapal & responden & presentase \\
\hline 1 & Sangat sejahtera & 2 & $20 \%$ \\
\hline 2 & sejahtera & 3 & $30 \%$ \\
\hline 3 & Cukup sejahtera & 1 & $10 \%$ \\
\hline 4 & Kurang sejahtera & 4 & $40 \%$ \\
\hline & jumlah & 10 & $100 \%$ \\
\hline
\end{tabular}

Sumber data hasil olah data MV Aisling 2018 
Table 4.5 menunjukkan tingkat kesejahteraan awak kapal, jika di lihat dari hasil olahan data menunjukkan kurang sejahtera,

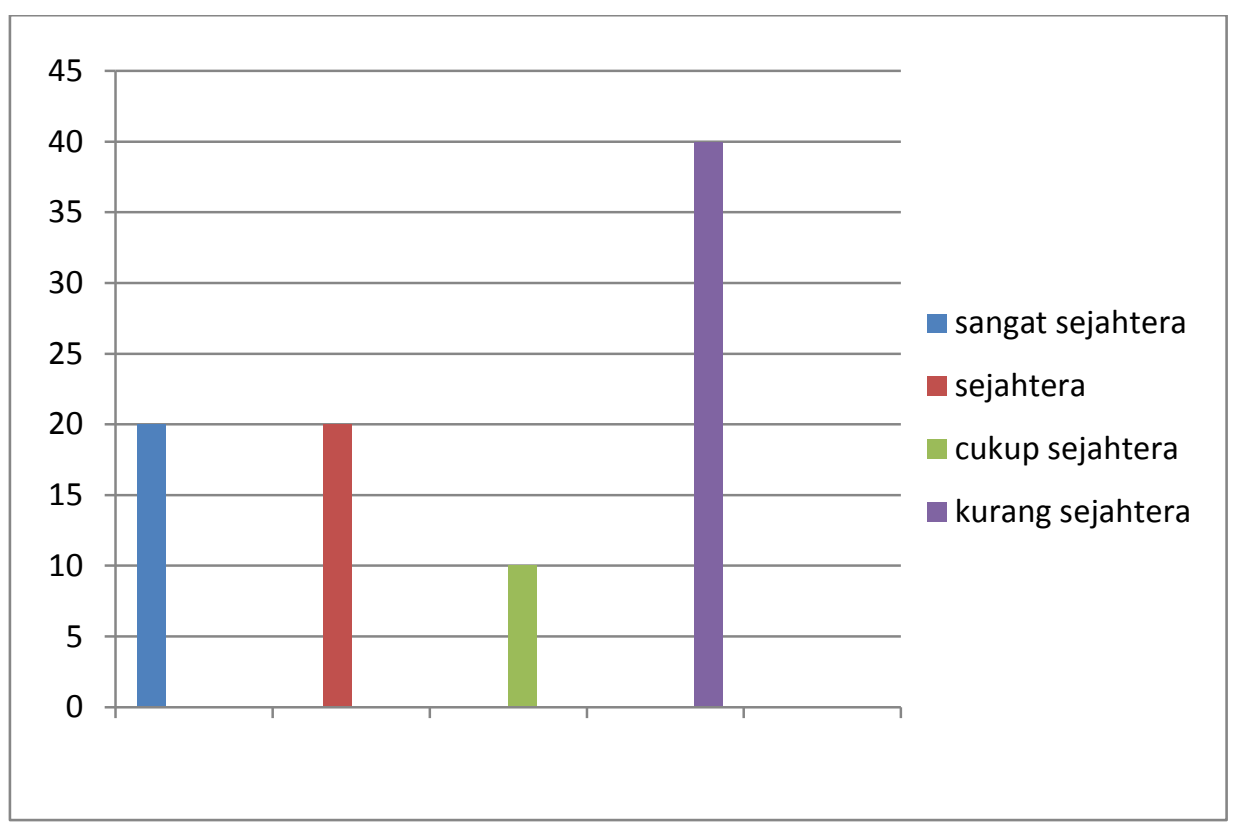

Sumber data : hasil olah data MV. Aisling

Dari grafik rekapitulasi di atas dapat di lihat tingkat kesejahteraan awak kapak dalam pemberian gaji, akomodasi ,maupun fasilitas lainnya menunjukkan nilai $40 \%$ kurang sejahtera.

\section{a. Minimnya Gaji awak kapal:}

Minimnya gaji para awak kapal ( anak buah kapal ) di sebabkan karena perusahaan tempat bekerja ,tidak bonavit, dimana perusahaan ini tidak mempunyai relation yang luas, sehingga kalah dalam marketing, dalam hal stevedoring untuk pengangkutan muatan, sehingga kapal ini jarang mendapatkan muatan untuk di angkut.

\section{b.Kurangnya Waktu istirahat :}

Istirahat bagi awak kapal ( anak buah kapal ) adalah merupakan hal yang terpenting bagi mereka yang ada di kapal, 
dimana awak kapal perlu beistirahat dengan baik, agar setelah menjalankan tugas berikut, berada dalam kondisi yang prima atau pit, sehingga dapat melaksanakan tugas dengan sebaik-baiknya, kurang istihat di sebabkan banyaknya kerja di kamar mesin atau di dek, karena banyak yang harus di perbaiki atau di refair, dalam aturan IMO istirahat minimal 10 jam sehari dan dalam seminggu adalah 72 jam, jika ini di patuhi ,tentu dapat beristirahat yang baik. Tetapi hal ini tidak di patuhi, karena banyak perbaikan yang harus di kerjakan.

\section{Akomodasi / Tempat stirahat}

Melikat kondisi Mv Aisling, dimana ruangan anak buah kapal tidak menggunakan alat pendingin, hanya ruangan nakhoda, mualim I, kepala kamar mesin dan masinis 1, yang di pasangi $A C$ split, untuk yang lain tidak ada AC, sehingga sangat tidak nyaman bagi awak kapal untuk beristirahat. Jika kapal berada pada daerah panas maka 'seperti di Arab, panas mulai bulan April sampai September dari $40 \mathrm{C}-50 \mathrm{C}$,. Jika melihat panas yang sangat panas tentu mempengaruhi waktu istirahat. Tempat istihat haruslah berAC agar nyaman untuk istirahat.

\section{A. Pembahasan}

\section{Kesejahteraan Pelaut :}

Kejahteraan adalah Dimana kondisi sesorang atau sekelompok, merasa nyaman, damai, bahagia, dan terpenuhinya kebutuhan hidup sehari-hari atau seseorang atau sekelompok bisa hidup layak. Jika standard gaji sudah dapat disamakan dengan Standard gaji Internasional, serta waktu kerja sudah sesuai dengan MLC.
a. Perlu Perbaikan Gaji anak buah kapal
b. Perlunya waktu yang Istrahat yang cukup
c. Akomodasi /tempat tinggal di kapal. 

d.Permakanan
e.Perlindungan \& perawatan Kesehatan

\section{SIMPULAN DAN SARAN}

\section{A. Simpulan}

Sesuai dengan analisa dan pembahasan yang sudah di lakukan maka dapat di simpulkan bahwa tingkat kesejahteraan awak kapal yang bekerja di atas kapal Aisling ,masih berada dalam kurang sejahtera untuk tingkat anak buah kapal, tetapi untuk tingkat perwira , mereka berada dalam sejahtera.. jika di presentasekan bahwa 40\% ,adalah anak buah kapal berada dalam kurang sejahtera, sedangkan sejahtera ada ada $30 \%$,sedangkan sangat sejahtera ada $20 \%$,dan cukup sejahtera ada 10\%, jadi jika di simpulkan yang terbanyak adalah $40 \%$ berada dalam kurang sejahtera.

\section{B. SARAN}

Penulis mengajukan saran sebagai upaya yang dapat direalisasikan dalam usaha mencapai tingkat kesejahteraan yang baik di atas kapal, yaitu seyoginya perusahaan memperhatikan tingkat kehidupan yang layak, mengupayakan gaji yang menjadi hak hakiki sebaiknya sesuai standard, serta akodomasi dan permakanan kirannya dapat di perbaiki agar mereka dapat beristirahat dengan baik.serta waktu kerja di atas kapal sebaiknya,di perusahaan harus sesuai dengan standard dalam MLC. 


\section{DAFTAR PUSTAKA}

[1]. Badan nasional Pemempatan dan Perlindungan Tenaga Kerja Indonesia. 2013. tentang tatacara perekrutan, penempatan dan perlindungan pelaut di kapal berbendera asing. Jakarta: Kepala Badan nasional Pemempatan dan Perlindungan Tenaga Kerja Indonesia .

[2]. International Transport Workers' Federation (ITF). (2014). Sebuah Panduan dari ITF Bagi Pelaut Untuk Memahami Maritime Labour Convention 2006. London.

[3]. Jack. c. Plano, dkk. 1982. The International Relation dictionary. Terjemahan Wawan Juanda, Third Edition, Clio Press Ltd.

[4]. Sugiyono. 2014. Metode Penelitian Kuantitatif, Kualitatif dan R \& D. Bandung. Alfabeta.

[5]. Rahim, Ruslan. 2014. Wawasan Kemaritiman. Jakarta : Universitas Halu Oleo.

[6]. Republik Indonesia. 2003. Undang-Undang Tentang Ketenagakerjaan. Jakarta: Presiden Republik Indonesia.

[7]. Republik Indonesia. 2003. Undang-Undang Tentang Pelayaran. Jakarta: Presiden Republik Indonesia.

[8]. Richard C. Snyder dalam James N Rosenau. 1962. The International and Foreign policy, The Free Press. London : Mac Millan Publicer.

[9]. Transport Workers' Federation. "Hak-hak Baru Apa Manfaat Konvensi Pekerja Maritim Untuk Anda" BULETIN PELAUT London No. 24/2010. 
[10]. Lembaran Negara Republik Indonesia. 2000. Peraturan Pemerintah Republik Indonesia Tentang Kepelautan Jakarta: Presiden Republik Indonesia.

[11]. Kepentingan Nasional, diakses dari <http://rosaliajasmine fisip13.web.unair.ac.id/artikel_detail84819SOH101\%20\%28P engantar\%20llmu\%20Hubungan\%2OInternasional\%29-Kepe ntingan\%20Nasional.html>p ada 8 Agust us 2014.

[12]. Konvensi Buruh Maritim 2006 Mulai Berlaku Pada 20 gustus2013,diaksesdarihttp://www.shippingindonesia.com/ highlights/ konvensiburuh-maritim-2006-mulai-berlaku-pada -20-agustus-2012> pada 10 Juni 2014.

[13]. Masa Depan Pelaut Indonesia Terancam, diakses dari $<$ http://possore.com/2014/02/13/masa-depan-pelaut-ndonesiaterancam/> pada 15 Agustus 2014.

[14] Negaramaritime,diaksesdarihttps://www.academia.edu/739 2029> pada 8 Agustus 2014.

[15]. Data Dephub RI, diakses dari <http://www.jurnalnet.com/konten.php? nama=Berita Utama\&topic $=88 \mathrm{id}=1642>$ pada 9 Agustus 2014

[16]. Garut, Popeye. "Implikasi MLC thdp Perekrutan \& Penempatan Pelaut." Diakses dari <https://groups.yahoo.com/neo/groups/ pelaut/conversations /messages/45813 >10 Desember 2013.

[17]. Hak pelaut dilupakan indonesia makin tersisih, diakses dari $<$ http://www.myedisi.com/jurnalmaritim/artikel/412/1162/> pada 20 Juni 2014.

[18]. Hambatan industry maritime, diakses dari <http://balianzahab. wordpress. com/makalahhukum/hukumpengangkutan/tran sportasimaritim/>pada 12Agustus 2014.

[19]. ILO, (2013). Industri Perkapalan Global Menetapkan Standar Baru .[online]http://www.ilo.org/jakarta/info/public/pr/WCMS _2 19970/lang--en/index.htm [20 agustus 2013].

[20]. Indoesia belum meratifikasi, diakses dari<http://www.indonesia maritime club.net/2013/09/29/indonesia-belumjuga-mera tifikasi-mlc/> pada 20 April 2014. 
[21]. Industry maritim, diakses dari <http://www.myedisi.com/maritime /artikel/ 124/315/>pada 25 Juni 2014.

[22]. International Transport Workers' Federation. (2014) Industri maritime sebagai pilar pembangunan bangsa,diakses dari tabloid.

[23]. Kepentingan Nasional, diakses dari <http://rosaliajasmine fisip13.web.un air.ac.id/artikel_detail84819SOH101\%20\%28 Pengantar\%20IImu\%20Hubungan\%20Internasional\%29-Kep entingan\%20Nasional.html>p ada 8 Agust us 2014.

[24]. Konvensi Buruh Maritim 2006 Mulai Berlaku Pada 20 Agustus 2013, diaksesdari <http://www.shippingindonesia .com/highlights/ konvensiburuh-maritim-2006-mulai-berlakupada-20-agustus-2012> pada 10 Juni 2014.

[25]. Masa Depan Pelaut Indonesia Terancam, diakses dari <http://possore. com/2014/02/13/masa-depan-pelaut-indon esia-terancam/> pada 15 Agustus 2014.

[26]. Negara maritime, diakses dari <https://www.academia.edu/7392 029> pada 8 Agustus 2014. 